\title{
Porselen Karo Üretimlerinde Konya Kili Kullanımı
}

\author{
Use of Konya Clay for Porcelain Tile Productions
}

\author{
Müge Tarhan1 ${ }^{1}$ i \\ Uşak Üniversitesi, Güzel Sanatlar Fakültesi, Seramik Bölümü, Ankara İzmir Yolu 8. km Bir Eylül Kampüsü, 64200 Uşak, \\ TÜRKIYE
}

\begin{abstract}
Öz
Porselen karolar düşük su emme, üstün mekanik ve de estetik özelliklerinden dolayı seramik kaplama malzemelerinde ilk sırada tercih edilen ürünler arasında yer almaktadır. Bu ürünlerin üretimlerinde düşük oranda demir içermesi ve yüksek plastiklik özelliğinden dolayı Ukrayna killeri kullanılmaktadır. Ukrayna kilinin ithal edilen bir hammadde olması ve her yıl fiyatının giderek artması nedeniyle porselen karo üretim maliyetleri de buna paralel olarak artmaktadır. Bu açıdan değerlendirildiğinde yerel hammaddelerin kullanılması şirketlere önemli bir maliyet avantajı sağlayacaktır. Çalışmada porselen karo bünye kompozisyonlarında Konya kilinin Ukrayna kili yerine kullanımı araştırılmış ve bünye teknik özellikleri üzerine olan etkileri belirlenmiştir. Standart porselen karo bünye kompozisyonunda kullanılmakta olan Ukrayna kili kademeli olarak azaltılmış yerine Konya kili ilave edilerek yeni bünye reçeteleri geliştirilmiştir. Geliştirilen bünyeler Uşak Seramik endüstriyel fırınlarında $1210^{\circ} \mathrm{C}$ 'de 52 dakikada pişirilmişlerdir. Bünyelerin tüm fiziksel ve optik özellikleri incelenmiştir. Sinterleme davranışları optik dilatometre cihazı ile incelenmiş, 1sıl genleşme katsayıları dilatometre cihazı ile ölçülmüştür. Bünyelerde gelişen fazlar XRD analizi ile belirlenmiş, mikroyapı incelemeleri taramalı elektron mikroskobu ile yapılmıştır. Sonuçlara göre bünyelerde Ukrayna kili yerine Konya kili kullanımı bünyelerin kuru mukavemet değerlerini, su emme ve pişme küçülme değerlerini arttırmaktadır. Sonuç olarak porselen karo bünyelerinde bünye kompozisyonunda bazı optimizasyonların da yapılmasıyla Ukrayna kilinin yerine Konya kili kullanımının uygun olacağı belirlenmiştir.
\end{abstract}

\section{Anahtar Kelimeler}

"Porselen karo, Konya kili, Ukrayna kili",

\begin{abstract}
Porcelain tiles are the most preferred products in ceramic tiles due to their low water absorption, superior mechanical and aesthetic properties. Ukrainian clays are used in the production of these products because of their low iron content and high plasticity, The Ukrainian clay is an imported raw material and its price increases every year, and so it increases the cost of the production of porcelain tiles. In this respect, the use of local raw materials will provide a significant cost advantage to ceramic companies. In the study, the use of Konya clay instead of Ukrainian clay was investigated in porcelain tile body compositions and the effects on the technical properties of the bodies were determined. For this purpose; Ukrainian clay was gradually removed and Konya clay were added to the standard porcelain tile composition of Usak Ceramic. The developed bodies were fired in Usak Ceramics industrial roller kilns at $1210^{\circ} \mathrm{C}$ for 52 minutes. All physical and optical properties of the bodies were examined. Sintering behaviors were examined by optical dilatometer and thermal expansion coefficients were measured by dilatometer. The phases developed in the body were determined by XRD analysis and microstructure investigations were made by scanning electron microscopy. According to the results, the use of Konya clay instead of Ukrainian clay in the body increases the dry strength values, water absorption and firing shrinkage values of the bodies. As a result, it was determined that the use of Konya clay would be possible with some optimizations in the composition of porcelain tiles.
\end{abstract}

Key Words

"Porcelain tile, Konya clay, Ukrainian Clay" 


\section{Giriş}

Seramik kaplama malzemeleri duvar karosu, yer karosu ve porselen karo olmak üzere temel olarak üç guruba ayrılmaktadır. Porselen karolar düşük su emme $(<\% 0,5)$, kimyasal dayanım, dona dayanım ve yüksek mekanik özelliklerinin yanı sıra sahip oldukları üstün estetik özellikleri bu ürünlerin hem iç hem de dış mekanlarda yer ve duvar kaplaması olarak kullanılmasını sağlamaktadır (Biffi 1999, Sanchez ve ark. 2001, Martin-Marquez ve ark. 2008, Zanelli ve ark. 2008 Tarhan 2010, Tarhan ve ark. 2017). Porselen karo üretimlerinde kullanılan hammaddeler plastik özelliğe sahip olanlar ve plastik özelliğe sahip olmayanlar olarak ikiye ayrılmaktadır. Plastik özelliğe sahip olan hammaddeler killer, diğerleri ise feldispat ve kuvarstır. Porselen karo bünye kompozisyonları genel olarak \% 25-40 plastik kil, \%0-15 kaolen, \% 40-50 feldispat ve \% 10-15 kuvars hammaddelerinden oluşmaktadır. Killer şekillendirmede kolaylık sağlamak ve ürünlerin yaş ve kuru mukavemetini arttırmak için kullanılırken, ergitici olarak kullanılan feldispatlar bünyelerin sinterlenmesini sağlayarak porselen bünyelere istenilen düşük poroziteli mikroyapısını kazandırır. Farklı kil minerallerinin, ergiticilerin ve kuvarsın miktarı, killerin minerolojik yapısına, tane boyut dağılımına ve ergiticilerle olan etkileşimlerine bağlı olarak değişmektedir (Villegas-Palacio ve Dinger,1996, Carty ve Senapati 1998, Tarhan 2010). Son y1llarda üretim teknolojisinde meydana gelen gelişmelerle $60 \times 120 \mathrm{~cm}, 100 \times 100 \mathrm{~cm}, 120 \times 120$ $\mathrm{cm}$ gibi büyük ebatlara doğru kaymaktadır. Seramik kaplama malzemelerinden porselen karo bünyelerinde üretilen karo boyutlarının gün geçtikçe artması, büyük ebatta yapılan bu ürünlerin özellikle aplikasyondan pişirime olan süreçte yüksek kuru mukavemete sahip olmalarını gerektirmektedir. Bünye reçetelerinde yaş plastik özelliğinden dolayı kuru mukavemet üzerinde en etkin olan hammadde killerdir. Porselen karo üretimlerinin özellikle büyük ebatlara doğru kayması bünye kompozisyonlarında yüksek plastiklikte killerin kullanımını zorunlu hale gerektirmektedir. Bunu yanı sıra sır aplikasyonu olmadan da üretilebilen porselen karo bünyelerinin pişme renginin estetik gereksinimlerden dolayı beyaz olması beklenir. Bünye renginin beyazlığı bünye kompozisyonlarında kullanılan hammaddelerde bulunan $\mathrm{Fe}_{2} \mathrm{O}_{3}$ ve $\mathrm{TiO}_{2}$ oranına bağlı olarak değişmektedir. $\mathrm{Fe}_{2} \mathrm{O}_{3}$ ve $\mathrm{TiO}_{2}$ diğer hammaddelere kıyasla en çok kil hammaddesinden gelmekle birlikte miktarının fazla olması bünye renginin koyulaşmasına neden olmaktadir. (Rado 1969, Worrall 1982, Vari 2000, Bonnet and Gaillard 2007,Cengiz 2011). Bu nedenle bu bünyelerde yüksek plastiklik ve beyazlık özellikleri ile Ukrayna killeri kullanılmaktadır. İthal edilen bu killer oldukça pahalı olup reçete maliyetlerini de önemli ölçüde arttırmaktadır.

Ülkemizde seramik karo üreticileri seramik kili açısından Türkiye'nin 2 büyük bölgesi olan İstanbul (Şile ve Kemerburgaz) ve Söğ̈̈t bölgesinden kil temin etmektedir. Bu bölgelerin dışında seramik sektörünün en önemli üreticilerine yakınlık bakımından ikinci derecede önemli kil potansiyeli olan bölgeler Çanakkale, Manisa, Kütahya, Afyon ve Konya'dır. Konya'nın Doğanhisar bölgesinde ekonomik öneme sahip killer Ayaslar ve Doğanhisar formasyonu içerisinde yer almaktadır. Konya-Doğanhisar'da 900 bin ton rezervli bir seramik kil yatağı işletilmektedir (Bayram 2012 ). Doğanhisar bölgesindeki killerin kullanımı yönünde yapılan çalışmalar incelendiğinde; tuğla, kiremit, seramik karo, çanak ve çömlek üretimi için uygun olabileceği belirlenmiştir. Bu çalışmada porselen karo bünyelerinde Konya-Doğanhisar kilinin Ukrayna kili yerine kullanımı ve bünye teknik özelliklerine etkileri araştırılmıştır. Çalışmada; Uşak Seramik firmasının standart porselen karo bünye reçetesinde kullanılan Ukrayna kili kademeli olarak azaltılmış ve yerine Konya kili ilave edilmiştir. Bu şekilde geliştirilen porselen karo bünyelerinin teknik özellikleri incelenerek Konya kilinin porselen karo bünyelerinde kullanılabilirliği araştırılmıştır.

\section{Materyal ve Yöntem}

\subsection{Kullanılan Hammaddeler}

Bünye geliştirme çalışmalarında 2 farklı tip kil, kaolen, sodyum feldispat, bentonit ve Konya kili kullanılmıştır. Kullanılan hammaddeler ve Konya-Doğanhisar bölgesinden temin edilen Konya kilinin kimyasal bileşimleri Çizelge 1 'de verilmiştir. Ukrayna kili ve Konya kilinin fiziksel pişme küçülme (\%), su emme (\%) ve renk değerleri Çizelge 2'deki fiziksel özellikler tablosunda verilmektedir.

Çizelge 1. Geliştirilen porselen karo bünyelerinde kullanılan hammaddelerin kimyasal bileşimleri (\% ağ.)

\begin{tabular}{lccccccccc} 
Hammaddeler & $\mathrm{SiO}_{2}$ & $\mathrm{Al}_{2} \mathrm{O}_{3}$ & $\mathrm{Fe}_{2} \mathrm{O}_{3}$ & $\mathrm{TiO}_{2}$ & $\mathbf{C a O}$ & $\mathbf{M g O}$ & $\mathrm{Na}_{2} \mathbf{O}$ & $\mathbf{K}_{2} \mathrm{O}$ & A.Z. \\
\hline Ukrayna Kili & 59,26 & 26,56 & 0,99 & 1,34 & 0,64 & 0,36 & 0,82 & 2,02 & 8,01 \\
İstanbul Kili & 62,24 & 22,64 & 2,81 & 1,22 & 0,22 & 0,44 & 1,28 & 2,04 & 7,11 \\
Kaolen & 69,14 & 20,77 & 0,62 & 0,74 & 0,23 & 0,06 & 0,17 & 0,28 & 7,99 \\
Sodyum Feldispat & 69,89 & 18,55 & 0,15 & 0,24 & 0,47 & 0,20 & 9,77 & 0,40 & 0,33 \\
Bentonit & 70,95 & 12,32 & 0,65 & 0,05 & 1,12 & 1,25 & 0,03 & 0,23 & 13,40 \\
Konya Kili & 64,43 & 22,79 & 1,31 & 1,04 & 0,30 & 0,50 & 0,44 & 2,36 & 6,73 \\
\hline
\end{tabular}


Çizelge 2. Ukrayna kili ve Konya kilinin fiziksel özellikleri (\% ăg.)

\begin{tabular}{lcc} 
& Ukrayna Kili & Konya Kili \\
\hline Kuru Mukavemet (kg/cm $)$ & 46,32 & 50,28 \\
Pişme Küçülmesi (\%) & 7,38 & 5,71 \\
Su Emme (\%) & 2,08 & 7,40 \\
$\mathbf{L}^{*}$ & 72,74 & 73,85 \\
$\mathbf{a}^{*}$ & 3,95 & 0,08 \\
$\mathbf{b}^{*}$ & 18,69 & 18,63 \\
$\begin{array}{l}\text { Issl Genleşme Katsayısı }\left(\mathbf{1 0}^{-7} \mathbf{C}^{-\mathbf{1}}\right) \\
(\mathbf{2 0 - 4 0 0} \mathbf{C})\end{array}$ & 61,72 & 67,07 \\
\hline
\end{tabular}

Konya kili ve Ukrayna kilinin XRD grafikleri Şekil 1'de verilmiştir. Kuvars, illit ve kaolinit fazları her iki kilde de tespit edilmiştir. Dikkati çeken en büyük fark killerin içerdikleri faz miktarlarıdır. Ukrayna kili daha fazla miktarda kaolinit fazı içerirken, Konya kili ise daha fazla miktarda illit fazı içermektedir. İllit kil mineralleri içerisinde en yaygın olan minerallerden biridir. Killerin yapısında bulunan illit fazı killerin mukavemetini arttırmaktadır (Anonim (2000a), Tarhan ve Tarhan 2019). Ukrayna kili ve Konya kilinin kuru mukavemet değerleri incelendiğinde (Çizelge 2) yapılan XRD analizini doğrular nitelike Konya kilinin Ukrayna kilinden daha yüksek kuru mukavemet değerine sahip olduğu görülmektedir. Bunun dışında killerin kuvars fazlarına ait pikler karşılaştırıldığında Ukrayna kilinin Konya kiline göre daha az miktarda kuvars fazı içerdiği görülmektedir. Ukrayna kilinin Konya kiline göre daha düşük 1sıl genleşme katsayısına sahip olması da doğrudan bununla ilişkilidir. Çünkü kristal yapıdaki kuvarsın 1 sıl genleşme katsayısı oldukça yüksektir (Kingery ve ark. 1976, Eppler and Eppler 2000, Tarhan ve Tarhan 2019) .

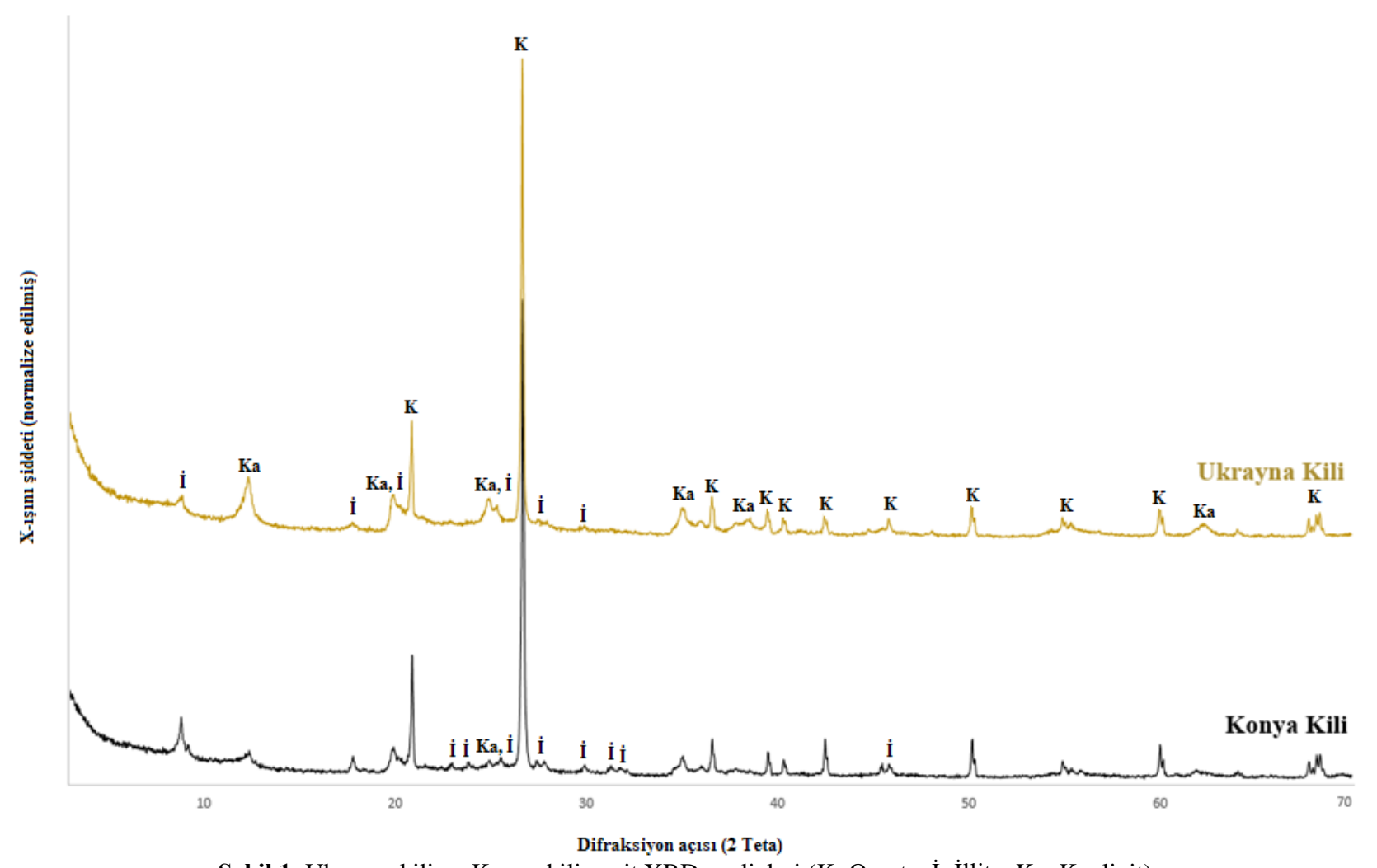

Şekil 1. Ukrayna kili ve Konya kiline ait XRD analizleri (K: Quartz, İ: İllite, Ka: Kaolinit)

\subsection{Bünye Geliştirme Çalışmaları}

Geliştirilen bünye kompozisyonlarında standart porselen bünye kompozisyonundan yola çıkılarak kullanılan Ukrayna kili azaltılmış yerine Konya kili kademeli olarak ilave edilmiştir. Standart porselen bünye reçetesi ile Konya kili ile geliştirilen bünye reçeteleri Çizelge 3 ’te verilmiştir.

Hammaddeler geliştirilen reçete oranlarına göre ve rutubet değerleri de dikkate alınarak tartılmıştır. Elde edilen hammadde karışımları laboratuvar tipi bilyalı değirmenlerde $45 \mu \mathrm{m}$ elek üstü bakiyesi \% 2-2,5 gelene kadar öğütülmüştür. Öğütme işlemi hammadde karışımlarına \% 0,8 sodyum silikat ve çamur yoğunluğu $1670 \mathrm{~g} / \mathrm{lt}$. olacak şekilde su ilavesi ile birlikte yapılmıştır. Öğütme işlemi sonrası çamurların yoğunluk $(\mathrm{g} / \mathrm{lt})$ ve elek bakiye $(+45 \mu \mathrm{m})$ değerleri ölçülmüş ve ardından etüvde $110^{\circ} \mathrm{C}$ sıcaklıkta kurutulmuştur. Daha sonra kurutulan çamurlar öğütülerek ve \%5-6 oranında nemlendirilerek toz granüller haline getirilmiştir. Nemin homojen olarak dağılmasının sağlanması amacıyla granüller bir gün boyunca bekletilmiş ve ardından $50 \times 100 \mathrm{~mm}$ boyutlarında $400 \mathrm{~kg} / \mathrm{cm}^{2}$ basınçla preslenerek şekillendirilmiştir. Hazırlanan numuneler $110^{\circ} \mathrm{C}^{\prime}$ de laboratuvar tipi 
etüvde 1 saat süre ile kurutulmuştur. Kurutulan numune karoların pişirimleri Uşak Seramik Fabrikası'nda porselen karo pişirim koşullarına göre $1210^{\circ} \mathrm{C}$ 'de 52 dak. lık pişirim süresinde gerçekleştirilmişstir.

Çizelge 3. Porselen karo bünye reçete kompozisyonları (\% ăg.)

\begin{tabular}{lccccc}
\hline & Std & K1 & K2 & K3 & K4 \\
\hline Ukrayna Kili & 12 & 9 & 6 & 3 & - \\
İstanbul Kili & 18 & 18 & 18 & 18 & 18 \\
Kaolen & 16 & 16 & 16 & 16 & 16 \\
Bentonit & 2 & 2 & 2 & 2 & 2 \\
Sodyum Feldispat & 52 & 52 & 52 & 52 & 52 \\
Konya Kili & - & 3 & 6 & 9 & 12 \\
\hline
\end{tabular}

\subsection{Karakterizasyon}

Çalışmada geliştirilen bünyelerin tüm fiziksel özellikleri belirlenmiştir. Bu kapsamda bünyelerin kuru mukavemet, \% pişme küçülmesi, \% su emme testleri yapılmış, standart bünye değerleri ile karşıllaştırmalı olarak TS EN 14411 (Grup BIa, E< \%0,5) standart test serisine göre değerlendirilmiştir. Numunelerin kuru eğilme mukavemeti testleri 3 noktalı eğme testi kullanılarak, su emme değerleri ISO 10545-3 vakumlu su emme test standardına göre yapılmıştır. Fiziksel testler için 5 numune ölçümünün ortalama değerleri alınmış ve standart sapma $\pm 1.5 \%$ olacak şekilde değerlendirilmiştir. Pişmiş numunelerin renk ölçümü (L*,a,b) Minolta Konica model renk ölçüm cihazı ile yapılmıştır. Bünye kompozisyonlarında kullanılan hammaddelerin kimyasal analizleri Rigaku NEX OC+ EZ marka ve model X- 1şını floresans spektometresi kullanılarak belirlenmiştir.Fiziksel test sonuçlarının değerlendirilmesine göre belirlenen bünye ile standart porselen karo bünyesinin sinterleme davranışları Misura ODHT HSM 1600/80 marka ve modeldeki optik dilatometre cihazı ile incelenmiştir. Ukrayna kili ve Konya kili ile pişirim sonrasında bünyelerde oluşan kristal fazların analizi XRD yöntemi ile tespit edilmiştir. XRD ölçümleri PANalytical X' Pert Pro MPD marka XRd cihazı ile yapılmıştır. Bünyelerin ısıl genleşme katsayısı değerleri dilatometre cihazı (Netzch 402 PC) ile ölçülmüştür. Bünyelerin mikroyapı görüntülerini elde etmek için numunelerin parlatılmış yüzeyleri incelenmiştir. Mikroyapı incelemeleri Phenom marka taramalı elektron mikroskobuyla yapılmıştır. Mikroyapı çalışmalarında; atom ağırlığına bağlı olarak faz ayrışımını sağlayan geri yansıyan elektronlarla (BEI) görüntüleme tekniği kullanılmıştır.

\section{BULGULAR VE TARTIŞMA}

\subsection{Fiziksel ve Optik Özellikler}

Standart porselen karo bünyesi ve Konya kili kullanılarak geliştirilen bünyelerin fiziksel özellikleri Çizelge 4'te verilmiştir. Sonuçlara göre Konya kili ilavesi ile geliştirilen bünyelerin kuru mukavemet değerlerinde belirgin bir artışın olduğu tespit edilmiştir. Ukrayna kili ve Konya kiline fiziksel test sonuçları (Çizelge 2) ve XRD analizi (Şekil 1) incelendiğinde Konya kilinin Ukrayna kiline göre daha yüksek oranda illit minerali içerdiği ve kuru mukavemet değerinin de daha yüksek olduğu görülmektedir. Killerin yapısında bulunan illit fazı killerin plastikliğini artırarak kuru mukavemetini arttırmaktadır (Anonim (2000a), Tarhan ve Tarhan 2019). Bu nedenle geliştirilen bünyelerde Konya kilinin artması ile birlikte kuru mukavemet değerleri benzer şekilde artmıştır.

Porselen bünyelerinde Ukrayna kili yerine Konya kili kullanılması düşük oranlarda bünyelerin su emme değerini çok etkilememiştir. Ancak Konya kili oranı \% 9'un üzerine çıktığında bünyenin su emmesi belirgin şekilde artmış ve fabrika standartları (su emme $<\% 0,1)$ üzerinde bir su emme değeri elde edilmiştir. Çizelge 2'de verilen killerin fiziksel özellikleri incelendiğinde Konya kilinin su emme değerinin Ukrayna kiline göre çok daha yüksek olduğu görülmektedir. Bu nedenle bünye kompozisyonlarında artan Konya kili miktarı ile su emme değeri artmıştır. Konya kilinin düşük oranlarda $(<\%$ ) kullanıldığı bünyelerde su emme değerinin belirgin bir artış göstermemesi ise bünyenin geniş bir ergime aralığına sahip olması ile açıklanabilir. Bunun yanı sıra bünyelerde Konya kili kullanımı bünyelerin pişme küçülme değerini arttırmıştır. Ancak yine artan Konya kili oranlarında (>\%9) su emmedeki artış ile birlikte pişme küçülme değerinde gözlenen azalma yüksek oranlarda Konya kili kullanımının bünyelerin sinterlenmesini zorlaştırdığını göstermektedir.

Bünyelerin beyazlık ( $\mathrm{L}^{*}$ ) değerleri incelendiğinde, Ukrayna kilinin azaltılması ve Konya kilinin artmasıyla beyazlık değerlerinde bir miktar atış tespit edilmiştir. Özellikle Ukrayna kilinin bünye reçetesinden tamamen çıkarıldı̆̆ 1 yerine Konya kilinin kullanıldığı K4 kodlu bünyenin beyazlık değerindeki artış dikkat çekicidir. Bunun nedeni Ukrayna kiline göre daha yüksek beyazlık değerine sahip olan Konya kilinin kullanılmış olmasının yanı sıra Ukrayna kili yerine tamamen Konya kili kullanılmış bünyenin daha az sinterlenmiş olmasıdır. Porselen bünyelerde sinterlemenin artması ve su emmenin düşmesiyle birlikte bünyelerde artan camsı faz nedeniyle beyazlık değeri düşmektedir (Tarhan 2010). 
Çizelge 4. Çalışılan bünyelerin fiziksel ve 1sıl özellikleri

\begin{tabular}{|c|c|c|c|c|c|}
\hline & Std & K1 & $\mathbf{K} 2$ & K3 & K4 \\
\hline Kuru mukavemet $\left(\mathrm{kg} / \mathrm{cm}^{2}\right)$ & 20,42 & 20,62 & 21,07 & 22,26 & 22,80 \\
\hline Pişme Küçülmesi (\%) & 7,94 & 7,95 & 8,14 & 8,34 & 8,08 \\
\hline Su Emme (\%) & 0,00 & 0,04 & 0,05 & 0,09 & 0,21 \\
\hline $\mathbf{L}^{*}$ & 73,53 & 73,49 & 73,71 & 73,87 & 74,33 \\
\hline $\mathbf{a}^{*}$ & 1,56 & 1,9 & 1,7 & 1,86 & 1,85 \\
\hline b* & 8,41 & 8,51 & 8,58 & 8,69 & 8,94 \\
\hline $\begin{array}{l}\text { Isıl Genleşme Katsayısı }\left(10^{-7} \mathrm{C}^{-1}\right) \\
\left(20-400^{\circ} \mathrm{C}\right)\end{array}$ & 72,99 & 73,04 & 73,33 & 73,51 & 74,46 \\
\hline
\end{tabular}

Porselen karo bünyelerinde ısıl genleşme katsayısı artan Konya kili miktarı ile birlikte artmaktadır. Konya kili Ukrayna kiline göre daha yüksek oranda $\mathrm{SiO}_{2}$ içermekte ve Ukrayna kiline göre daha yüksek ssıl genleşme katsayısı değerine sahiptir. (Çizelge 1,Şekil 1 ve Çizelge 2). Bu Konya kilinin Ukrayna kiline göre daha fazla miktarda kuvars fazına sahip olması ile açıklanabilir. Çünkü kristal yapıdaki kuvarsın ısıl genleşme katsayısı amorf yapıdaki kuvarstan oldukça yüksektir (Kingery ve ark. 1976, Eppler and Eppler 2000). Bundan dolayı bünyelerde artan Konya kili oranıyla birlikte 1sıl genleşme katsayısı değeri de artmaktadir.

\subsection{Pişirim Davranışı}

Konya kili kullanılarak yapılan bünye geliştirme çalışmalarında; standart bünye teknik özelliklerine en yakın olarak en yüksek oranda Konya kili kullanılabilecek reçete \% 9 oranında Konya kilinin kullanıldığ 1 K3 bünyesidir. Bu nedenle porselen karo bünyelerinde Konya kilinin sinterlenme davranışına etkisini belirlemek için standart bünye ile \% 9 oranında Konya kili kullanılan K3 bünyesinin sinterlenme davranışları incelenmiştir. İlk olarak bünyeler için sinterlemenin en hızlı olduğu sıcaklık değeri tespit edilmiş ve bu sıcaklık değeri $\left(1210^{\circ} \mathrm{C}\right)$ tepe sıcaklığı olarak kabul edilmiştir. Sinterleme davranışlarının incelenmesi için olarak öncelikle $80^{\circ} \mathrm{C} / \mathrm{dk}$ ile $500^{\circ} \mathrm{C}$ 'ye çıkılmış ardından $50^{\circ} \mathrm{C} / \mathrm{dk}$ ile $1210^{\circ} \mathrm{C}^{\prime}$ ye çıkılarak ve tepe sicaklı̆̆ında $10 \mathrm{dk}$ beklenmiştir. Şekil 2'de verilen sinterleme eğrileri zamana karşı bünyenin küçülme davranışı ve artan sıcaklık ilse sinterleme oranını göstermektedir. Her iki bünyenin de $1210^{\circ} \mathrm{C}$ 'de ve $10 \mathrm{dk}$.lık bekleme süresinde lineer küçülmesi durmuştur. K3 bünyesi bu sicaklık ve sürede hiçbir deformasyona uğramadan küçülme davranışı gösterirken, standart bünye uygulanan bekleme süresinde yaklaşık 5. dakikadan sonra hafif bir genleşme göstermeye başlamıştır. Bu durum uygulanan sicaklık ve/veya sürenin standart bünye için fazla pişmeye neden olduğunu göstermektedir. Bu nedenle K3 bünyesinin standart bünyeye göre sinterlenmesinin daha yüksek sicaklık ve/veya daha uzun süre gerektirdiği söylenilebilir. Bu da porselen karo bünyelerinde Ukrayna kili oranının azalması ve Konya kili kullanımı ile birlikte bünyelerin sinterleme sıcaklık ve/veya süresinin arttığını göstermektedir. Çizelge 4'te verilen Konya kili kullanımındaki artışla birlikte su emme değerlerindeki artış da bu sonucu doğrular niteliktedir. Bunun yanı sıra Şekil 2'de verilen optik dilatometre eğrileri incelendiğinde Konya kili kullanımı ile bünye küçülme değerinin arttığı görülmektedir. Bu da yine Çizelge 4’te verilen pişme küçülmesi verilerini doğrular niteliktedir. 


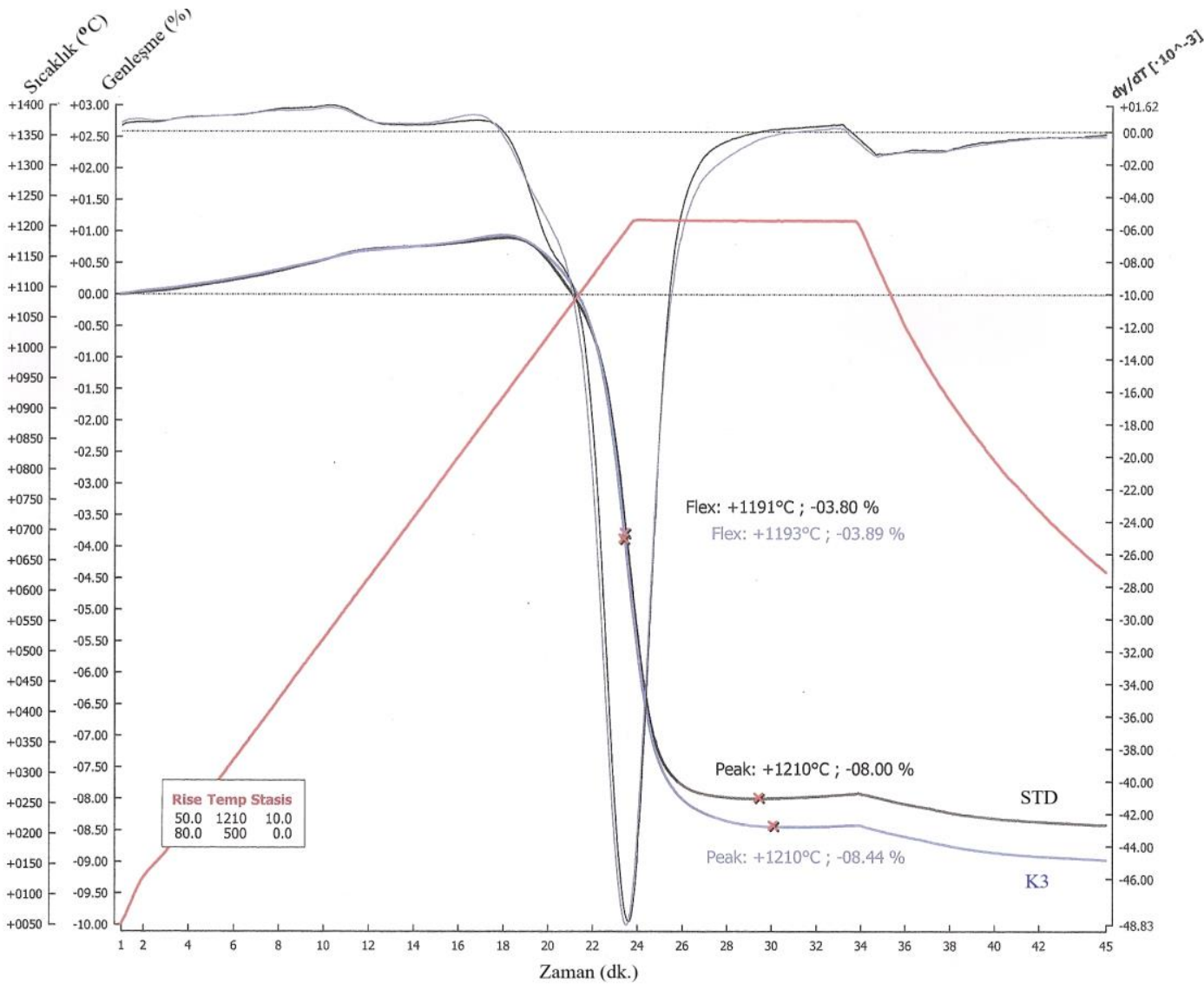

Şekil 2. Standart ve K3 kodlu porselen karo bünyelerine ait dilatometre eğrileri.

\subsection{Faz Analizi}

Standart bünye ile Konya kili kullanılarak geliştirilen porselen karo bünyelerinin XRD analiz sonuçları Şekil 3 'te verilmiştir. Analiz sonuçlarına göre tüm bünyeler birbirlerine benzer şekilde kuvars, müllit ve kalıntı albit fazlarını içermektedir. Müllit fazı, porselen bünyelerin sinterlenme sürecinde bünye kompozisyonlarında bulunan kil minerallerinden gelişir. Porselen karo bünyelerinde kısa pişirim sürelerinden dolayı albit fazının bir kısmı camsı faz içerisinde ergimeden kalmaktadır. Bu nedenle albit fazı kalıntı faz olarak mikroyapıda bulunmaktadır (Manfredini ve ark. 1995, Iqbal ve ark. 2000, Esposito ve ark. 2005, Carbajal ve ark. 2007, Tarhan 2010). Ana faz olarak yapıda bulunan kuvars da yine albit fazı gibi kalıntı bir fazdır. Çizelge 1 ve Şekil 1 'de verilen Ukrayna kili ve Konya kilinin kimyasal ve XRD analizlerine göre Konya kili Ukrayna kiline göre daha yüksek oranda kuvars içermektedir. Bu nedenle bünyelerde artan Konya kili miktarı ile birlikte bulunan kalıntı kuvars pik şiddetinin de artması beklenmiştir. Ancak yapılan XRD analizlerinde çok belirgin bir fark gözlemlenmemiştir.

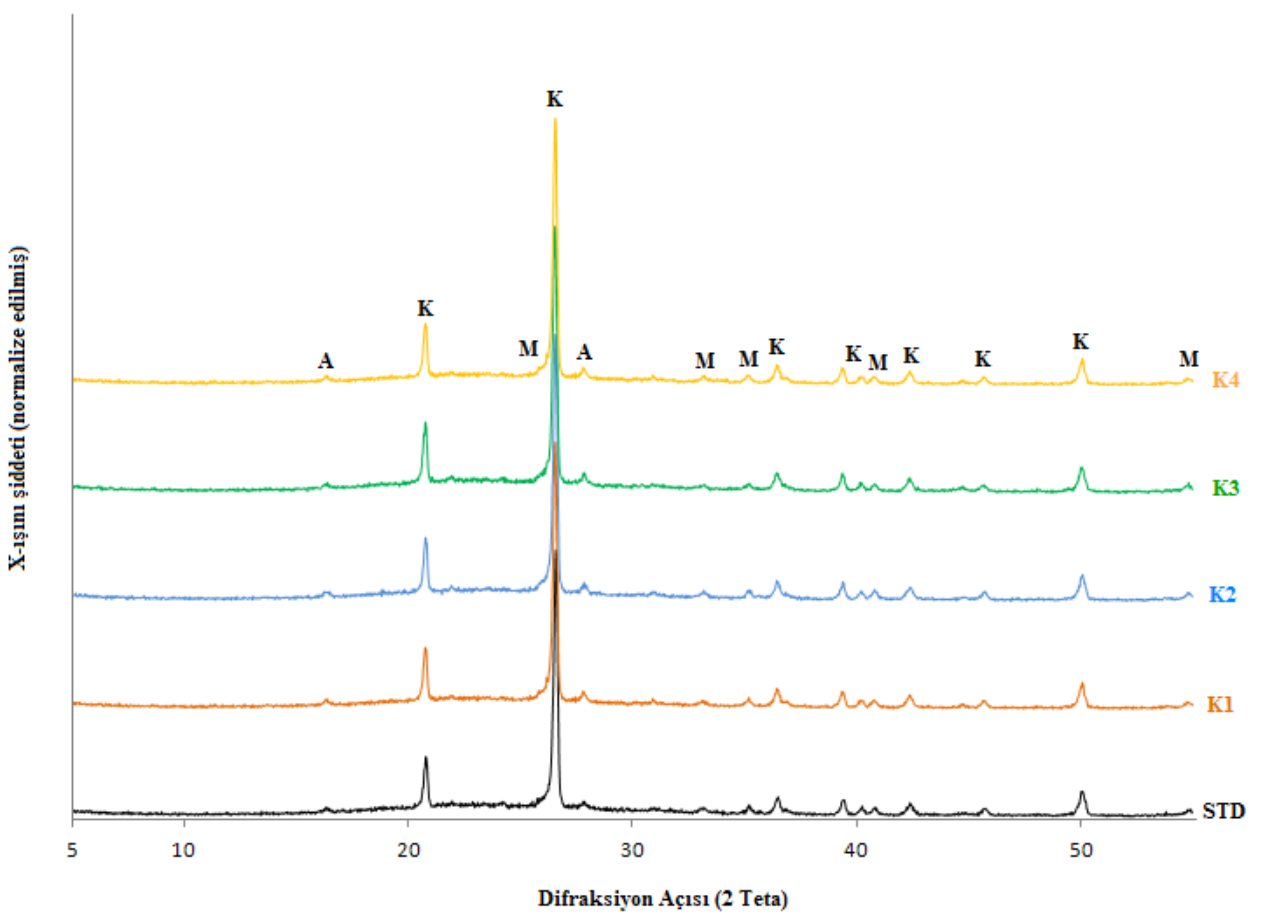

Şekil 3. Geliştirilen porselen bünyelere ait XRD analizleri (A: Albit, K: Kuvars, M: Müllit) 


\subsection{Mikroyapı Analizi}

Standart bünye ve K3 kodlu bünyeye ait numunelerin parlatılmış yüzeylerinden alınan geri yansıyan elektron görüntüleri Şekil 4'te verilmiştir. Geri yansıyan elektron görüntülerinde ağır elementler diğer elementlere göre daha beyaz görünmektedir. Mikroyapı görüntülerinde koyu gri ton ile görülen kısımlar kuvars tanelerini, açık gri-beyaz gibi görülen kısımlar müllit kristallerini ve siyah renkli kısımlar da poroziteleri göstermektedir. Standart ve K3 bünyelerinin birbirlerine oldukça benzer şekilde düzensiz şekilli kuvars kristalleri, müllit kristalleri ve porları içerdiği görülmektedir. Porselen karo bünyelerinin sinterleme sürecinde kuvarsın bir kısmı camsı fazın içinde çözünürken, bir kısmı çözünmeden kalıntı kuvars olarak bünye mikroyapısında kalır. Sinterlemenin son aşamasında $\alpha \rightarrow \beta$ kuvars dönüşümünden dolayı kuvars tanelerinin içerisinde ve etrafinda çevresel çatlaklar oluşmaktadır (Tarhan 2010, Tarhan 2019). Her iki bünye mikroyapısında da kalıntı kuvars taneleri ile kuvars taneleri içerisinde ve çevresinde oluşan mikroçatlaklar gözlenmektedir.

Porselen bünyelerde sinterleme sırasında oluşan camsı faz viskoz akışla porları doldururarak yoğunlaşmayı sağlar. Bu sayede boyut sıralarına göre porlar elimine edilirler (Amoros ve ark. 2007, Tarhan 2010). Mikroyapı görüntülerinde dikkat çeken noktalardan biri az da olsa porların boyut ve miktarlarındaki farklılıktır. Porselen bünye kompozisyonunda Konya kili kullanımı ile birlikte por boyut ve miktarının biraz da olsa arttığı görülmektedir. Bu da porselen bünyelerde Ukrayna kili yerine Konya kili kullanımının bünyelerin sinterlenmesini zorlaştırmasını ve bünye su emme değerindeki artışı açıklamaktadır.
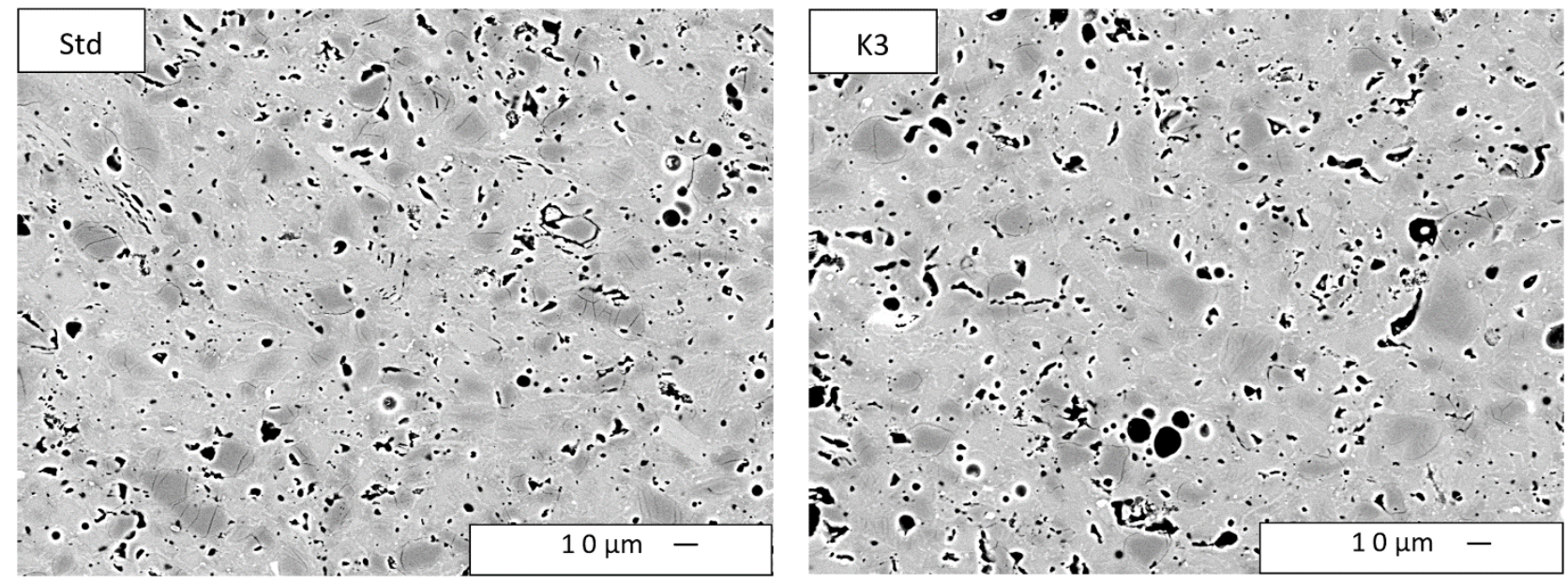

Şekil 4. Std ve K3 bünyelerinden alınmış geri yansıyan elektron görüntüsü.

\section{Genel Sonuçlar}

Bu çalışmada Konya kilinin porselen karo bünyelerinde ithal bir kil olan Ukrayna kili yerine kullanılabilirliği araştırılmıştır. Ukrayna killeri porselen karo bünyelerinde, sahip oldukları yüksek plastiklik özellikleri ile bünyelerin kuru mukavemet değerini arttırmaları ve yüksek beyazlık değeri nedeni ile tercih edilmektedir. Özellikle son yıllarda porselen karo ürün ebatlarının giderek büyümesi ve dikdörtgen ebatlara doğru kayması ürünlerin yüksek kuru mukavemet değerlerine sahip olmalarını gerektirmektedir. Bu nedenle ithal edilen Ukrayna killerinin kullanımı neredeyse zorunlu hale gelmiştir. Yapılan çalışmada Ukrayna kilinin yerine kullanılabilirliği araştırılan Konya kilinin fiziksel özellikleri değerlendirildiğinde Ukrayna kiline bir alternatif olabileceği tespit edilmiştir. Porselen karo bünyelerinde Ukrayna kilinin azaltılarak yerine Konya kili kullanılması bünyelerin kuru mukavemet değerini arttırmaktadır. Bünye kompozisyonlarında özellikle Ukrayna kili yerine artan Konya kil miktarı ( $\geq \% 9)$ bünyelerin su emme ve pişme küçülme değerlerini de belirgin şekilde artırmıştır. Bununla birlikte bünyelerde Konya kili kullanımı bünyelerin deformasyon davranışını belirleyen ısıl genleşme katsayısı değerini de arttırmaktadır. Genel olarak elde edilen tüm teknik özellikler değerlendirildiğinde, porselen karo bünyelerinde Konya kilinin kullanılarak Ukrayna kil oranının azaltılması reçetede yapılacak bazı optimizasyonlarla mümkün olabilecektir. Ukrayna kili yerine Konya kili kullanılması halinde bünye kompozisyonları, su emme-pişme küçülme ve deformasyon değerlerini işletme standartlarında tutacak yönde optimize edilmelidir.

\section{Teșekkür}

$\mathrm{Bu}$ çalışmada desteklerinden dolayı Uşak Seramik San. A.Ş.'ye teşekkür ederim.

\section{Kaynaklar}

Amoros, J.L., Orts, M.J., Garcia-Ten, J., Gozalbo, A. (2007), Sanchez, E., Effect of geen porous texture on porcelain tile properties. Jour. of Eur. Ceram. Soc., 27, 2295-2301.

Anonim (2002a), Applied ceramic technology, Volume I, SACMI IMOLA s.c. a r.l., Italy. 
Bayram, F. (2012), Doğanhisar İlçesi’nin kil başta olmak üzere maden türünden yeraltı kaynaklarının potansiyellerinin tespiti, T.C. Mevlana Ajansı Kalkınma Projesi, TR52-11-TD01/118, Konya.

Biffi, G. (1999), Porcelain stoneware - production manual and methods of use, Gruppo Editoriale Faenza Editrice S.p.A., Faenza.

Bonnet J.P. and Gaillard J.M. (2007), Ceramic Materials, Processes, Properties and Applications, Philippe Boch and Jean-Claude Niepce, ISTE Ltd., 96.

Carbajal, L., Rubio-Marcos, F., Bengochea, M.A., Fernandez, J.F. (2007), Properties related phase evolution in porcelain ceramics, Journal of the European Ceramic Society, Volume 27, Issues 13-15, 4065-4069.

Carty, W.M. ve Senapati, U. (1998), Porcelain-raw materials, processing, phase evolution, and mechanical behaviour, J. Am. Ceram. Soc., 81(1), 3-20.

Cengiz Ö., (2011), Monoporoza (monoporosa) duvar karolarının pişirim koşullarının geliştirilmesi, Doktora Tezi, Anadolu Üniversitesi Fen Bilimleri Enstitüsü, Eskişehir, 165.

Eppler, R. A.and Eppler, D. R., (2000), Glazes and glass coatings, American Ceramic Society, Westerville, Ohio.

Esposito L., Salem A., Tucci A., Gualtieri A., Jazayeri and S.H., 2005. The use of nepheline-syenite in a body mix for porcelain stoneware tiles, Ceramic International, 31, 233-240.

Iqbal, Y., Messer, P.F., Lee, W.E. (2000), Microstructural evolution in triaxial porcelain, J. Am. Ceram. Soc. 83 (12), $3121-$ 3127.

Kingery, W.D., Bowen, H.K. and Uhlmann, D.R., (1976), Introduction to Ceramics, John Wiley \& Sons., Inc., Canada.

Manfredini, T., Pellacani, G.C., Romagnoli, M. (1995), Porcelainized stoneware tile, Am. Ceram. Soc. Bull., 74,76-79

Martin-Marquez, J., Ma. Rincon, J. Ma. and Romero, M., 2008. Effect of firing temperature on sintering of porcelain stoneware tiles. Ceramic International, 34, 1867-1873.

Rado P., (1969), An Introduction to the Technology of Pottery, Second edition, Pergamon Press, The Worecester Royal Porcelain Company Ltd., 99.

Sanchez, E., Orts, M.J., Garcia-Ten, K., Cantavella, V. (2001), Porcelain tile composition effect on phase formation and end product, Am. Ceram. Soc. Bull. 80 (6), 43-49.

Tarhan B., Tarhan M. and Aydın T., 2017. Reusing sanitaryware waste products in glazed porcelain tile production, Ceramics International, 43, 3107-3112.

Tarhan, M, 2010. Porselen karo bünyelerinde sinterleme hızı-kompozisyon ilişkileri. Doktora Tezi, Anadolu Üniversitesi Fen Bilimleri Enstitüsü, Eskişehir, 230.

Tarhan B., (2019) Usage of fired wall tile wastes into fireclay sanitaryware products. J Aust Ceram Soc., https://doi.org/10.1007/s41779-018-0285-1

Tarhan, M. ve Tarhan B., (2019), Afyon kilinin porselen karo bünyelerinde kullanımının araştırılması, Uluslararası Mühendislik ve Araştırma Dergisi, https://doi.org/10.29137/umagd.433307.

Villegas-Palacio, S. and Dinger, D.R.,1996. PSD effects on firing properties of porcelains I-II, American Ceramic Society Bulletin, 75, n. 7, 71-83.

Worrall, W. E. (1982), Ceramic raw materials. Second edition. Pergamon Press, University of Leeds, Leeds,UK.

Zanelli, C., Baldi, G., Dondi, M., Ercolani, G., Guarini, G. and Raimondo, M., 2008. Glass-ceramic frits for porcelain stoneware bodies: Effects on sintering, phase composition and technological properties. Ceramic International, 34, 455-465. 